\title{
PARTISANSHIP AND THE PARTY SYSTEM
}

\author{
Philip E. Converse and Roy Pierce
}

The defining properties of party identification long established for the United States fail with some frequency to be replicated in electoral systems abroad. A number of plausible suggestions have been made to account for this system-level variability: Most of these have some face merit, but none taken alone is adequate to provide a full cross-system explanation. Variation in party system size or fractionalization has recently been discussed as another source of differential dynamics of party loyalties. Unfortunately, the conventional means of assessing party identification properties are subject to rather severe artifacts, typically ignored, when comparisons are made across systems of very different party size. The conceptual stakes underlying key methods options for such comparisons-most notably, between continuous and discrete statistical tools-are examined. The use of continuous statistics for systems of very multiple parties rests on an assumption that voters do in some degree regard these party systems as imbedded in a continuous space. A simple test for this assumption is mounted in four systems and unsurprisingly it shows very clear support. Analysis of residuals beyond this obvious result add several points of less obvious information about the distribution of party affect in such systems.

Students of electoral politics have long focused on the role of psychological attachments to political parties in accounting for key aspects of continuity and change in voter preferences. Within the context of the United States, a phenomenon of party identification was invoked to account for the fact that voters reported defecting from their generally preferred party in the short run, but tended to return "home" to it after such defections at rates greatly beyond chance (Campbell et al., 1960). These party loyalties, once formed, are not immutable: They may be constantly updated around the edges to reflect assessments of party performance on the current scene (Brody, 1977b; Brody and Rothenberg, 1988; Fiorina, 1981). But for most voters most of the time, the predominant causal flow is from partisan attachments to other more specific political sentiments, including vote choices, rather than the reverse. Such identifications in the United States are more stable than vote partisanship. Thus, when the student of Ameri-

Philip E. Converse, Center for Advanced Study in the Behavioral Sciences, 202 Junipero Serra Blvd., Stanford, California 94305-8710. Roy Pierce, University of Michigan. 
can elections needs an analytic variable that is both potent and relatively exogenous, at least for short-run uses, it is hard to find anything that even seriously competes with a measure of party identification.

For democratic systems abroad, however, the story may be quite different. Initially in the 1960s scholars in Europe and elsewhere seized upon the party identification concept for uses in their own electoral studies. This interest turned to disillusionment in some countries, however, when it was discovered that certain key dynamic features of party identification as demonstrated for the United States could not be replicated locally (e.g., Budge, Crewe, and Farlie, 1976). Actually, the situation was one step more frustrating, in that some glints looking like the American identification phenomenon appeared everywhere, but they were often different glints. ${ }^{1}$ Disillusionment reached its peak with evidence that in certain systems, most notably the Netherlands, voter testimony about party loyalties was if anything less stable than party choice at the polls, and in any event it seemed to arise as a post hoc adjustment after a shift in vote choice (Thomassen, 1976).

It is not, of course, surprising to find that party identification dynamics show some cross-system variability. Indeed, in the first extended description of the phenomenon it was shown inter alia that even within the United States such identifications were more strongly developed in states that officially required voters to declare a generic party of preference than in those with no such electoral requirement (Campbell et al., 1960). Nonetheless, party identification dynamics are seen to pivot in some degree on such basic psychological processes as the need for simple cues to help order a complex reality, and curves of social learning. These are not, presumably, phenomena that are present in some cultures but not in others.

The purpose of this paper is to continue reporting on a series of investigations that we have carried out in recent years, designed to make broader sense of the cross-national evidence concerning party identification. Data archives now enjoy an abundance of electoral surveys worldwide with one or another version of a partisanship measure. Given our immediate purposes, we are unable to harness all of this empirical richness here. We must restrict our empirical work to those studies in the archives with appropriate party identification measures carried out on representative national samples followed longitudinally. ${ }^{2}$ It is the longitudinal criterion that eliminates the vast majority of archived electoral studies, but we must hew to this stipulation because we are interested in the dynamics of partisanship over time.

\section{SYSTEM VARIATION IN PARTISANSHIP: SUGGESTED SOURCES}

Numerous studies of cross-national variation in the apparent workings of partisanship are frankly descriptive, intended merely to document that system differences exist in these regards. Some studies, however, attempt to 
explain post hoc why empirical studies have shown "unusual" patterns in this or that polity. It is worth beginning with a brief review of some of these suggestions.

As always, in confronting discrepant results it is useful to consider the possibility of methods artifacts before engaging in strenuous theorizing about the meaning of observed differences. Early on, for example, it became clear that some evidence of anomalies from abroad was suspect because inferences about dynamic properties were being made from data collections at a single point in time. In an earlier paper in this series we also noted that other points of apparent failure to replicate American patterns were based on measures of short-term affect toward political parties that bore little resemblance to the conventional party identification measure (Converse and Pierce, 1985). Discarding results from nonequivalent methodologies has helped somewhat to shrink the range of apparent anomalies, although it has fallen far short of resolving them away.

Beyond this methodological brush-clearing, more substantive explanations for cross-national differences have hinged on contrasts in electoral system properties. For example, Butler and Stokes (1969), noting that British voters seemed less likely than Americans to express a sense of abiding partisanship even when changing a vote to another party, linked the contrast to differences in the normal task voters face at the polls in the two countries. The American voter, confronting a ballot requiring selection of many candidates at multiple levels of office, can align many decisions at once by saying, "I am basically a Democrat, although now and again I can be lured into voting for an especially attractive Republican." Such a statement recognizes a primary identity and a grounds for occasional defection. British voters, asked to vote but once at one level, may feel it odd or inconsistent to report that they voted conservative but really feel attached to Labour. This interpretation is highly plausible and widely accepted, although no systematic review of the proposition over a wider cross-national range of balloting conventions has to our knowledge been carried out.

Variations in electoral history have also been invoked to account for other cross-national differences in patterns of psychological partisanship. It has been postulated, and spottily confirmed, that true partisan identifications take extended periods of time to develop, and that patterns of identification in new democratic systems should look quite different from those in mature systems (Converse, 1969). Perhaps most notably, data from an early slice of time in a new system should show older voters less strongly identified with their parties than younger ones, or a direct reversal of the customary relationship.

More recently, we have reported evidence that a similar reasoning applies, at least in France, to newly emergent parties or formations whose names are frequently changed. In such systems, "standard" party identifica- 
tion dynamics are much more clearly observed among identifiers of the few parties such as the Communists and Socialists that have been on the scene for several generations with essentially the same names. Similarly, we were able to demonstrate that in pockets of France, where only two main parties have been pitted against each other locally for many years, partisan dynamics also resemble those of the two-party United States more closely (Converse and Pierce, 1986). Hence multiparty systems appear to breed somewhat different patterns of partisanship. And when, as in the French system, the complexity is increased by both brisk turnover and persistent renaming of many of these competing parties, the same parsimonious theory would alert us to look for patterns of party attachment that lie between those of totally new party systems and those systems like the United States where the major parties have had nominal continuity for well over a century.

Recently, several scholars have called attention to the fact that in foreign multiparty settings the dynamics of partisanship seem to resemble the American prototype more closely for the largest parties than for the smaller ones (Richardson, 1986; Barnes, 1990). Thus, for example, Barnes notes that in the Netherlands and West Germany of the later 1970s, strength of partisanship is, in the American style, positively correlated with age for the two major party groupings, but where other smaller parties are the objects of these loyalties, identification strength declines with the age of the voter.

These are fertile observations and have an obvious bearing on the crossnational party identification riddle. Certainly if small parties evoke, for whatever reason, systematically different dynamics of partisan feeling than large ones, it stands to reason that aggregate data on partisanship should look different from systems of many parties, most of which will be of necessity "minor," than from "two-party" systems, where there are typically no minor parties at all.

At the same time, these observations do not in themselves account in any systematic way for why partisanship has different dynamics within major and minor parties. Actually, one such explanation lies close at hand. Although gross historical exceptions can be found, minor parties tend far more often than not to be recent entrants in their party systems. Thus, for example, in the contrasts cited by Barnes (1990, p. 251), we can calculate the differences in "historical depth" of the implantation of what are coded as major and minor parties. Given that we are dealing with Dutch parties of enormously differing size, we have weighted the ages of the several parties by their levels of current support. When we do this, we find that the groupings considered to be "major" parties had on average been established parts of the Dutch political scene for about seventy years at the time the Barnes data began, whereas the "minor" parties had on average only 
been organized for about twenty years, and thereby had intruded on the scene after a large fraction of the electorate being surveyed had been socialized into voting within the system. The original theory of accumulating party loyalties would predict that in such a sequestered group of newer Dutch parties the age-partisanship relationship would still be negative, rather than the more familiar positive, just as is now reported. Thus what is important about minor parties may not be mainly that they are minor but that they are new. ${ }^{3}$ And more generally, since a proliferation of what are called minor parties is a monopoly of highly multiparty systems, and by definition cannot occur in mere two-party systems, we have a theoretical basis for expecting aggregate partisanship dynamics to differ significantly as a function of party system size.

While these surmises are reasonable enough, our further investigations have been driven by a suspicion that greater party turnover is not the only source of divergent identification dynamies in multiparty systems. The sheer size of the party system in itself is likely to be an important factor. It surely has not been lost on many observers that the birthplace of "party identification theory" was in the smallest and most ancient competitive party system in the world, while the sharpest empirical challenge as to the generality of U.S. theories has come from the Netherlands, which has as large a party system as has existed in the world in the recent period. Just how large that party system is depends on definition, although it is symptomatic that the partisanship codes prepared for the Dutch election studies of the early 1970s have places for more than thirty parties or distinctive coalitions thereof. Surely we might expect the phenomena of psychological partisanship to differ somewhat between a two-party and a thirty-party system!

For much of the remainder of this paper we shall consider in detail what tools we must have to pursue reliably in a cross-system format the implications of party multiplicity for the dynamics of partisanship, since in a degree that is often ignored, conclusions in this context are distressingly affected by tool choice.

Our first need is for a way to measure party system size by something more meaningful than sheer numbers of parties. Not only does such a simple count become arbitrary in the fringe of minuscule formations but taken literally it can be positively misleading. Even when the two major U.S. parties are capturing well over 99 percent of the nation's votes, some definitions would contend that the system still has five or more vote-receiving parties. Happily we can avoid such foolishness because Rae (1967) has proposed an excellent index of "party fractionalization" that takes account of both the size and the distribution of party strength (in popular votes, legislative seats, or whatever). We have adopted this index gratefully. 
Rae's index pivots off the probability that two randomly selected voters (seats) will be of the same party. It takes a value of zero fractionalization when there is but a single monolithic party in a system and a value of one when every voter (seat) is a party unto itself. It is mainly moved, of course, by the number of parties in a system, but it is additionally affected by the relative size of those parties. Thus a system with two parties of equal size shows a higher index value $(F=.500)$ than a two-party system in which one party has three times the strength of the other $(F=.375)$. Similarly, a thirty-party system dominated by one party capturing half of the vote would rate as much less fractionalized than a system with thirty parties of equal strength. These are all highly desirable properties in talking about party system "size." Our investigations have not been limited to the one concept of fractionalization, although it is the central independent variable in much that we have done.

Choosing analytic tools to quantify the crucial features of partisan change and constancy for our dependent variables turns out to be a much more complicated matter than is commonly understood. This is true because each of the major options in the traditional toolkit tends to color the impressions that we receive even from the same batch of partisanship data. A little thought makes clear that each traditional option commits us to a certain model of the phenomenon we are hoping to compare across systems. In short, we are at a point where method and substance suffer strong interactions. In the sequence of our investigations, it has been important to understand the conceptual implications of our choice of methods as clearly as possible from the outset.

\section{THE INTERACTION OF METHOD AND SUBSTANCE}

Assessments of partisan dynamics always hinge in one way or another on the observed constancy of partisanship, be it constancy in profession of a loyalty, constancy in the vote for a party or, better yet, the interplay of the two. Constancy has in turn been assessed in virtually every one of the most influential items in the comparative literature on party identification in simple percentage terms (cf., for example, Butler and Stokes, 1969). For a given party, the question is what percentage of those favoring the party at time-1 continue to favor it at time-2.

This is a most natural reflex in treating two-party systems. However, the format has been casually extended to larger party systems (Thomassen, 1976; Norpoth, 1978; LeDuc, 1981; Eijk and Niemoeller, 1983). Crosssystem comparisons can be facilitated if a single number can be found to summarize the stability of partisanship in a system between two points in time. The typical expression is the percent stable or "loyal," that is, who 
repeat the same partisanship at both measurements. In an $n$-party system, this single number arises from the sum of the entries down the main diagonal of the $n=n$ turnover table for the partisanship measure.

There is nothing intrinsically wrong about such a calculation, and under many circumstances it is exactly what we should want. However, like any mere measure, it obscures some things while clarifying others. In a degree not properly appreciated, it commits the analyst to a particular view of the substantive phenomenon of party change.

There are alternative gauges of constancy. To take a familiar example, when we assess the constancy of party identification for individuals over time in the United States, we often start with positions on the conventional seven-point scale at two time points. From such data we can array a turnover tabulation and count people on the main diagonal, which is the percentage way, at the level of nominal measurement. Or we can view our measurements as an approximation to a continuous variable and move to assessments of constancy in the form of continuity correlations or regression analyses.

These procedures are analogous but not identical. Furthermore, they often give somewhat different subjective impressions. Continuity correlations for party identification in the U.S. case, which usually are over .8 for moderate time lapses, seem to soar toward a perfect value of 1.00 , especially if we keep in mind some inevitable fuzz of error, and therefore sound like a glass more than half full. The percentage calculation, which often emphasizes the proportion off the main diagonal (not giving exactly the same response twice), implies considerable change and thus may seem like a glass more than half empty. The main source of the differential impression is of course that the correlation gives credit for some stability when change off the main diagonal is very slight, while the percentage mode treats such slight departures as equivalent to huge changes.

It is an obvious impediment to the accumulation of knowledge if exactly the same underlying data can be presented in two reasonable alternate forms: one that impresses the reader with great stability and the other with great instability.

We shall shortly argue that choices between these rival analysis formats must ultimately rest on the substance being investigated. There is one circumstance, however, in which the correlational mode would seem intrinsically superior. This is when we need to compare stability across variables measured at much different levels of fineness. Suppose, for example, that we wish to compare our partisan stability data based on the seven-point party identification scale with another partisanship measure, such as a difference in the thermometer ratings given to Republicans and Democrats, which would likely show twenty or thirty distinct values rather than a mere 
seven. If we proceed in a percentage way, the proportion on the main diagonal will be much smaller in the turnover table partitioned thirty ways than in the table partitioned seven ways. Correlational assessments are very nearly insensitive to such partitioning differences, however, if the lesser number of partitions is much more than a handful.

All of which brings us face to face with the real problem troubling our specific investigation: Highly fractionalized systems will introduce many more partitions in our tabulations than will less fractionalized ones. If we proceed to make cross-system comparisons in the familiar percentage way, we become vulnerable to some very strong artifacts.

We have constructed some artificial data in Figure 1 to convey just how strong these confounding influences may be. To prepare the figure we randomly sampled paired values from a bivariate normal distribution with a Pearsonian correlation of about .69. We chose this level because it is near the center of a zone familiar for certain types of partisanship continuity associations.

We arrayed these paired observations in a scatter diagram. This scatter diagram we may think of as an "underlying situation" (continuous). We then introduced varying partitions to represent different degrees of party fractionalization. These partitions are of course hypothetical, although at points we have used party strength divisions from actual systems for a note of reality. Thus Figure 1(C) is modeled after West German data of the early 1970s; Figure 1(D) is modeled from Dutch data of the same period, reduced to the most substantial eleven parties in the systems. In both of these instances party size is conveyed by the size of the line segment occupied: The large parties are wide and the small parties are thinner. In Figure $\mathbf{l}(\mathrm{E})$ we have altered this construction assumption by making each one of the eleven parties equal in width.

Once these partitions representing parties are entered, we can retrieve from the diagrams some party cross-tabulations that permit us to proceed in the conventional percentage mode, gauging party constancy by the fractions of these populations falling on the main diagonals. And we find resounding "system differences": As party systems become more fractionalized, the constancy of partisanship, gauged in percentages loyal, declines precipitously. The most important point, however, is that by construction there are no system differences in the actual "underlying situation": Individuals have exactly the same locations at both points in time in every panel. We emphasize this invariance in the bottom row of the figure by showing that identical continuity correlations are associated with each "system."

We can also subject these pseudodata to other pseudoanalyses. As shown in the figure, we ask whether the percentages constant in their party differ 


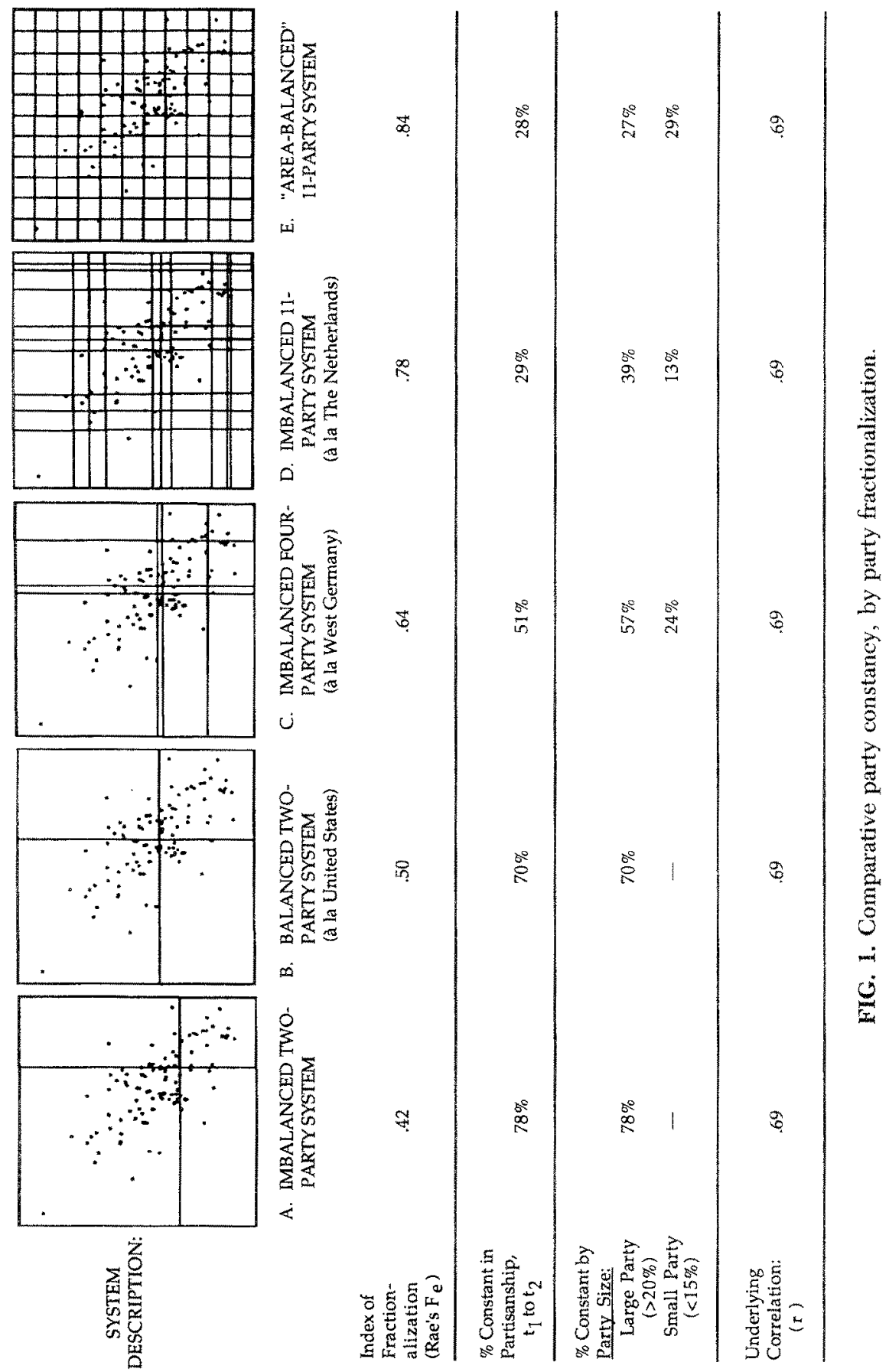


between small and large parties. We find that for the most part they do differ and quite dramatically: Patrons of small parties show much less "loyalty" than do patrons of large parties, this being exactly the finding we noted had recently been reported from genuine party systems analyzed comparatively in a percentage mode (Richardson, 1987; Barnes, 1987). We remarked that this finding, treated substantively, might be no more than a special case of the original party identification theory, since small parties tend more often than not to be new ones for which deep attachments have not yet accumulated. On the other hand, the fact that strong differences in percentage constant appear even within our pseudodata raises the possibility that this result is method-dependent. Just why this difference arises, however, becomes clearer when we note that it does not appear in Figure $1(E)$, where parties are designed to be equal in their "breadth," if not in the sizes of their followings.

How general are the "pseudoresults" in Figure 1 otherwise? For example, we have modeled the underlying situation in Figure 1 as bivariate normal. Would we get analogous outcomes with other underlying population distributions? The answer is positive for the most part. To be sure, we could concoct tortured distributions that would generate other aggregate results if we concentrated large clusters of cases in certain boxes and left other boxes empty. But such deliberate "rigging" would be pointless and unfair. For a very large range of distributions, including all realistic ones, the effects we see would be essentially duplicated. This is true because as we partition a space more finely, the average number of elements per category or $n$-dimensional box has to decline accordingly.

Indeed, it is because this is so elementary that Figure 1 belabors the obvious. The only reason we have bothered to "draw a diagram" is that the percentage mode of assessing party constancy is almost everywhere the method of choice; and in comparing systems the method is usually employed without any mention of any associated artifacts to be expected as we move from simple systems to highly fractionalized ones.

To recognize the severity of this problem does not, however, in itself provide any clear guidance as to which analysis format we should use for our investigations. For such guidance we must turn to a consideration of what each format is assuming more specifically about the substance of our party loyalty inquiry.

\section{Conceptual Stakes in Rival Analytic Models}

It is not hard to build a strong defense for the conventional percentage treatment of party change. After all, there is nothing in the original theory of party identification to suggest that the dynamics of identification with a 
given party may differ according to what further parties there are in the system. The focus is on some single party and a person either belongs to it (by some specified criterion) or does not. Similarly, a member either remains loyal to this party or defects from it. The issue is the person's location with respect to the party boundary, a matter that is intrinsically dichotomous and one for which percentage statements are ideal.

From this viewpoint, treatment of political systems as continuous party spaces, while perhaps of gripping interest in its own right, requires elaborate assumptions, many of which seem gratuitous. Such treatments are often vague about the defining character of the space, whether it be $n$ dimensions of policy, voter likes and dislikes, or something else. Whatever the spaces are made of, it is not clear that voters consensually perceive party competition in any continuous space, although the use of continuous statistics presumes that they do. Worst of all, a continuous-space view leads directly away from what is central to the party loyalty problem, which is the boundary of the given party. The emphasis on the continuity of the space tends to fuzz out boundaries; and if we insist on laying out some boundaries within the space then we can only do so at the cost of further unexamined and perhaps unexaminable assumptions concerning how the space is carved into party regions, be it as a function of membership size as in Figures 1(A-D), or in the equal-size blocs of Figure $\mathbf{l}(\mathrm{E})$, or in accord with any of a large number of other rival assumptions. In short, the continuous-space treatment costs a lot of strong assumptions and then merely distracts us from the core of our substantive problem.

This argument carries a lot of truth. It fails, however, to come to grips with the potentially severe artifacts in making percentage comparisons across party systems of very different size, as represented by Figure 1. It is not clear how the percentage method could deal with the artifact beyond denying that it exists, on the substantive ground that party boundaries defining a zone of loyalty are absolute and invariant in their effects on partisan dynamics without regard to party size or the context defined by neighboring parties. On the other hand, it is exactly this kind of invariance that has been called into question by the early cross-national evidence. And if we can work our way to more reliable cross-system comparisons of these dynamics, which the correlational mode offers, then perhaps we can get a better sense of where existing theory is oversimplified.

Continuous-space statistics in effect equate systems for party size, thereby providing ground for comparisons between systems. It is important, however, to understand substantively just what assumption we are committing ourselves to at this point. In effect we assume that a system thirty parties "broad" is in some real sense no broader than a system with only two parties. This is equivalent to denying that the range of policy alternatives con- 
sidered at some level in a thirty-party system is in some absolute sense fifteen times greater than in a two-party system; or that the dislike felt by some citizen at one extreme of the system toward a citizen at the other extreme is fifteen times more intense. It postulates that the breadth of such systems is about the same. ${ }^{4}$

Of course it is important to point out that actual party programs presented to the public are likely to cover a much wider range of alternatives in a thirty-party system than in a two-party one. But this can naturally follow even if in all systems the range of discussed alternatives is essentially the same. That is, the most extreme political fringe in systems both large and small is advocating equally radical alternatives: The difference is that in a thirty-party system this fringe can be an actual party presenting a program, whereas in the two-party system the fringe is merely a weak pressure group at the far flank of one of the two parties. This is to say that while a tiny extreme-left splinter party in the Netherlands does indeed offer a more radical option to voters than does the Labour Party in Britain, its advocacies are not significantly different in their radicalness from those advocated by the most extreme left fringe of the left wing of the Labour Party, and they are surely not in any sense five or ten times more radical than their Labour Party counterparts, in the way that would be implied by a doctrine that the range of political alternatives being conceived at any level in a system is a direct integral function of the number of parties in the system.

This view of ultimate system equivalence is a "story" that can claim a lot of verisimilitude. We can use the same reasoning working from the voter end of the picture to tell an equally convincing "story" why partisan allegiances might show different dynamics in a very large system than they do in a small two-party one. In effect, the interparty distances should be experienced as being smaller and less forbidding in a very large system than in a small one. For the voter preferring one of only two parties, the system has an aura of Manichean dualism: The world is divided into the good guys and the bad guys. Deserting the good guys in any general and permanent way is like being for $\sin$. On the other hand, there is a sense of moral relativism that a very large system conveys with its many party options. There are always parties that are close neighbors, and the voter can do some roaming around a mere quadrant of the space without any feeling of selling his or her soul to the real devil twenty parties away.

Thus on several counts the continuous vision of party spaces is a congenial one in addition to offering a useful solution to artifacts of comparison across systems of variable size. It does, as alleged, tend to blur our sense of party boundaries, or it alternatively requires us to make some rather arbitrary assumptions as to where they are located. This is a potential cost, but 
it has an easier solution than might appear, in the sense that with the continuous-space methods we can arrive at some interesting tests of the effects of party boundaries, provided only that we are willing to keep them in mind.

\section{An Enlarged View of Partisan Dynamics}

We feel no obligation to decide that voters in multiparty systems see its parties exclusively in either the continuous way or as mere nominal categories. We feel that there is evidence to imagine that they see it both ways at once, although admittedly some individuals may be more sensitive to one perspective than the other. Indeed, conceptually (methods aside) we find that we can combine the two perspectives in what is quite an attractive enlargement of our view of partisan dynamics in such systems.

From this combined perspective, voters do view these large systems in some degree as continuous spaces, which means among other things that voter motion across portions of these spaces fits simple "geographic mobility" rules such that short distances are traversed more readily and frequently than long ones or, in the terms of our substantive problem, near party alternatives are more attractive than distant ones. We state this as an assumption, but it is obviously a hypothesis that we can and shall test in the final section of this report.

At the same time, parties themselves have some magnetic power as nominal categories so that voter migration in these spaces is additionally affected by where party boundaries fall. That is, parties in these spaces are like cells with membranes that are more or less permeable. These boundaries can be passed through, but their existence creates some impedance, perhaps mild, slowing down the movement.

Working with continuous-space assumptions we could in principle test a variety of interesting hypotheses about the dynamics of motion in these spaces. For example, using the proposition that interparty distances are in some sense important for behavior, we could hypothesize that movement between neighboring parties in large party systems is routinely greater than between the parties in a two-party system. On the other hand, if party boundaries have some impedance value, then we should find that motion over larger distances (thereby crossing multiple boundaries) should be less in large systems than over comparable distances in a two-party system with but one boundary to cross.

Of course the original party identification theory might argue that only one set of boundaries exercises any significant impedance, that being the boundaries of the party to which special loyalty is felt. It clearly should take some extra "escape velocity" fueled by political aggravation to decide to 
depart from a party of identification completely. But once one has exited across the boundary of one's own prior party, then the crossing of other party boundaries may have no further effect beyond the standard minimization of distance traveled.

In sum, if we take a combined view of the decision processes shaping the dynamics of partisanship, rather than arguing that one view or the other is the accurate one, we stimulate a variety of hypotheses that can help put the whole phenomenon of partisanship in more general perspective.

\section{Multidimensionality and Imperfect Information}

Let us briefly recognize two important complications that we have chosen to ignore in the early stages of our investigation. First, we are aware that party spaces in large systems often have some multidimensionality to them even in the minds of the voters (for an early investigation of the subject, see Converse, 1966a). This fact complicates things like the establishment of distances traveled by voters through such systems. At the same time, there is evidence that most such large systems have one clear principal dimension, whatever secondary ones may coexist with it. Therefore as a first approximation we shall enjoy the simplification of thinking unidimensionally.

The second problem involves imperfect information. It is not surprising that the continuous view of party spaces has been associated with rational models of political behavior. Such a view assumes vastly more information of the voter than is necessary for the nominal party model. A totally uninvolved voter who knows only that his family is Democratic and pays no other attention to politics can vote perfectly well in the United States. But the rationalist view assumes that the voter is continually scanning party options to find the closest alternative. It implies that he or she knows much more about any single party than does our Democratic loyalist; and if there are thirty parties in the system, it is clear that he or she must technically have orders of magnitude more of political information than the inattentive loyalist.

As is well known, we can expect to find some voters in every system, however large and complicated it may be, who know their system in high detail and with deadly accuracy. As is equally well known, such voters are usually a very small percentage of their electorates; and where party systems are truly large and complex, there are large fractions of the electorate for whom a modest phrase like "imperfect information" is quite charitable. We have elsewhere done a detailed empirical charting of the distribution of knowledge about the complex French party system in its electorate (Converse and Pierce, 1986). At the level of recall, many French voters cognize 
the system as little more than a three-party one, although those who cognized but three of eleven or so parties active at the time did tend to be aware of major alternatives rather than three neighboring parties in a single quadrant of the party space. However, knowledge of additional parties is thin and scattered, meaning that the party space can be quite idiosyncratically "deformed" in its shape, relative to the perfect information counterpart.

Nonetheless, it has been our strategy to proceed as far as we can ignoring the problem of heterogeneous information.

\section{TESTING THE CONTINUOUS-SPACE ASSUMPTION}

We have now laid out the conceptual infrastructure for our investigation and discussed its interaction with our choice of analytic tools. Our final task in the first stage is to verify the generality of the key assumption that voters in multiparty systems tend to see them in reasonable degree as continuous spaces. In a sense the verification is trifling, since mounds of confirming if not well-systematized evidence are extant. On the other hand, the tests are worth reporting here, since they generated certain serendipitous discoveries on the side that have had impact on our subsequent work.

More specifically, our hypothesis is that voters in systems with more than two parties give evidence of seeing other parties than their own first preference as located at varying political "distances" from themselves and that the voters respond to these further parties affectively as a strong function of these distances.

We began by locating those single studies within each of our multiparty systems that contained measures of (1) self-location on a left-right scale; (2) perceived left-right locations reported for each major party in the system; and (3) feelings of individual voters toward each of these parties. We then proceeded to check the hypothesis on aggregated data in the following fashion. First, it is known that there is a good deal of scatter in voter perceptions of the left-right positions of given parties in such systems, presumably due to imperfect information. On the other hand, it is also known that the total sample means of these attributions, party by party, bear a close resemblance to the much more consensual, or less scattered, locations given the same parties by knowledgeable elite observers. Therefore we took the means of these perceived locations over each system sample as a fixed and semiobjective measure of party locations, permitting us to say how distant in unidimensional terms each party was from every other.

Then for the sympathizers of each party in the system we took the mean affect reported toward each major party, including one's own party. ${ }^{5}$ This produced a square matrix of affect means between all parties. This matrix 
was not symmetric because partisans of Party A could have different aggregate feelings toward Party $\mathbf{B}$ than were reciprocated from $\mathbf{B}$ to $\mathrm{A}$. We chose to leave this source of variability in the analysis and simply regressed all averages for interparty feelings on interparty distances. Since warm feelings were keyed to larger values, our hypothesis called for an inverse relationship between distance and affect. It is not necessarily true that we would get a linear covariation between these two scalings, although the sizes of intercorrelations can in this context be taken as indicators of goodness of fit to the simplest linear model.

The basic output over the several tests run in this aggregated form is summarized in Table 1. Within each of our multiparty systems there are towering relationships between continuous gradations of felt distance and gradations of affect. The tightness of these relationships varies with system size in a way that might well be predicted on methodological grounds alone, although it is also plausible that there may be higher dimensionality and more anomalies of mutual perception in very fractionalized systems. That is, the three highest relationships out of nine estimated, actually approaching $r=-1.00$, all occur in the four-party German system, whereas the three lowest relationships all occur in the Dutch data.

In any event, the main message of Table $I$ is loud and clear: Voters in these systems do see parties as differentially placed in some kind of contin-

TABLE 1. The Party Distance/Affect Relationship in Four European Multiparty Systems

\begin{tabular}{|c|c|c|c|c|c|c|}
\hline \multirow[b]{2}{*}{ Country } & \multirow{2}{*}{$\begin{array}{c}\text { Study } \\
\text { Year }\end{array}$} & \multirow{2}{*}{$\begin{array}{c}\text { Effective } \\
N \text { of } \\
\text { Individuals* }\end{array}$} & \multirow{2}{*}{$\begin{array}{c}\text { Nof } \\
\text { Party } \\
\text { Objects }\end{array}$} & \multirow{2}{*}{$\begin{array}{l}\text { Paired } \\
\text { Observ. }\end{array}$} & \multicolumn{2}{|c|}{$\begin{array}{c}\text { Regression } \\
\text { Output }\end{array}$} \\
\hline & & & & & $b$ & $(r)$ \\
\hline France & 1967 & 831 & 6 & 36 & -.72 & -.87 \\
\hline \multirow[t]{3}{*}{ W. Germany } & 1976-1 & 1,607 & 4 & 16 & -1.09 & -.96 \\
\hline & $1976-2$ & 1,250 & 4 & 16 & -.97 & -.97 \\
\hline & $1976-3$ & 977 & 4 & 16 & -.98 & -.98 \\
\hline \multirow[t]{3}{*}{ Netherlands } & 1970 & 1,291 & 10 & 100 & -.63 & -.81 \\
\hline & 1971 & 798 & 8 & 64 & -.67 & -.74 \\
\hline & 1972 & 572 & 10 & 100 & -.69 & -.81 \\
\hline \multirow[t]{2}{*}{ Norway } & 1981 & 534 & 7 & 49 & -1.13 & -.83 \\
\hline & 1985 & 488 & 7 & 49 & -1.00 & -.86 \\
\hline
\end{tabular}

\footnotetext{
*Although regressions rest on aggregated data and each respondent contributes multiple affect values, these entries provide an approximate number of independent individual contributions to the aggregate solution.
} 
uous space in ways that bear directly on their own gradations of liking and disliking the relevant party objects. It should be kept in mind the correlations are as high as they are in part because of the degree of aggregation to party-level data that we imposed as a shortcut on what was expected to be a rather routine demonstration. In fact we have looked at the version of the distance-affect relationship with the affect term disaggregated to the individual level in a few instances: For France, the aggregate $r$ of -.87 reduces to an individual $r$ of -.54 ; and for the Netherlands in 1970, the value of -.81 reduces to -.51 . These reductions are suggestive of some of the idiosyncratic variability in information and perception that our aggregation drives out. But it would be hard to view the data in either form and still claim that our use of continuous spaces in formulating our hypothetical Figure 1 is far-fetched or unwarranted.

Once past the routine test, some unexpected further results emerge from the same analysis. With distance-affect correlations already in the $.80 \mathrm{~s}$ and $.90 \mathrm{~s}$, it is tempting to assume that most variance remaining unaccounted for in affect can be little but measurement error. We rapidly discover, however, that this is very far from the case. Since we are dealing with repeated panel waves in all countries of Table 1 save France, we can take residuals from the simple linear regression of affect on distance at more than one time for a given country and compare them. We find them strongly correlated.

In the West German case, for example, very little of the original variance in aggregated affect is left unaccounted for by the simple distance variation: only 7.6 percent of it for Wave I, 5.3 percent for Wave II, and 3.8 percent for Wave III. Yet these very sparse residuals are still correlated at $r=.58$ between Waves I and II, and at .70 between Waves II and III. The corresponding coefficients for the Netherlands are .71 and .67, respectively. And the correlation of residuals for the two Norwegian waves is $r=.88$ ! These residuals are obviously no mere remainder of error noise and they deserve more systematic study.

Since characteristic high or low residuals are linked repeatedly to specific party pairs (one partisan group as subject, reacting to another party as object) in these systems, it is easy to detect what the additional sources of variance are. Some were foreseen. For example, in the Dutch case, religious division adds a second dimension impinging on expressions of affect. Partisans of Protestant parties tend to take a dimmer view of Catholic parties (and vice versa) than the simple linear left-right model predicts. This secondary effect is, however, much weaker than expected: It is, in fact, barely more than discernible.

Two strong departures from linearity are reflected in these residuals. These include (1) a substantial bonus of positive affect for one's own party 
and (2) a preference for large parties over small ones. Both effects have an important bearing on the argument we have been developing.

The first bonus is very clear in any scatter diagram of the distance-affect relationship. For the most part affect toward parties other than one's own defines a pretty clear line in these systems, as the strong correlations of Table 1 imply. But if this neat line based on assessments of all other parties is extended to the intercept representing a distance of zero, or an imputed affect for one's own party, then it turns out routinely that such an extrapolation understates the warmth of feeling actually reported by voters for their own parties. People like their own parties much more than their outparty feelings would suggest.

By reestimating our regression with own-party distance and affect set aside, we can isolate just how large this bonus of affect is, especially where we have more data points than for the small- $N$ German case. For France it is about 17 points, for the Netherlands about 24 points, and for Norway about 28 points. The relative magnitudes here are evocative, since the literature based on more direct measurements suggests that party identifications are rather dilute in the aggregate in France and are on the strong side for Norway. The absolute magnitudes are equally impressive, in view of the fact that the predictions for affect toward other parties empirically cover only about a 50-point range in these systems. Thus the bonuses are running one-third to one-half of that range. Since these bonuses appear for all "own" parties from system to system, it becomes less surprising that the residuals from the simple linear analysis show such strong intercorrelations over time within each system.

The bonus that registers in this continuous-space analysis also calls into question the concern associated with a preference for nominal measurement, to the effect that a continuous-space mode risks ignoring the crucial boundaries that set one's party off from others in the system. The bonus seems to be an excellent way of expressing the special "grip" of party identification. It conveys neatly the greater escape velocity of disenchantment that may be required to move out of one's chosen party than to shop freely across alternative parties once the escape has taken place.

The second repetitive departure from linearity is not nearly as marked as the first bonus effect. However, in all systems there is a clear tendency for voters to react more favorably to the largest system parties than toward the smallest, with basic distance controlled. Thus, for example, residuals left after the distance-affect analysis are correlated $(r)$ with party size (as indexed by voting strength) at levels of $.67, .72$, and .54 in the three Dutch waves, at .50 and .65 for Norway, and at .91 in the sole trial for France.

It should be remembered that these lavish correlations have been formed from highly aggregated mean data and rest on only six to ten paired 
values, with outlying values not excluded. But they offer further reason for the fact that the minimal residuals from our sturdy linear solutions show such strong cross-time correlations within each system. Stably large party objects persistently show positive residuals and the tiny parties show negative ones,

This link between our residuals and party size has a final implication for our discussion. In an earlier section we pointed out that with other things equal, voters should show more interparty change in highly fractionalized systems than in smaller ones, although the grounds are entirely artifactual. Due to the same artifacts, it could be inferred that other things equal, voter turnover should be proportionally larger for smaller parties than for large ones. The reasoning here is impeccable, and the caution is an important one.

On the other hand, the analysis of residuals suggests that voters tend to deprecate small parties at levels over and above the negative feelings that naturally intensify as perceived political distances increase. In principle we might be able to deduce from the data in hand whether this surplus of negativism is associated with the size of these parties or with their novelty. In practice this is difficult because of analytic instabilities associated with fairly strong collinearity between party size and party novelty, combined with our very limited number of relevant well-fractionalized systems. Pitting party size against party age in predicting the residuals would lead to a clear conclusion for the Netherlands that size dominates the relationship and age is irrelevant. For Norway, the same test suggests a more even balance, with age being slightly more important than size. However, these results are mixed and unstable because they tend to hinge on the residual affect felt toward a single anomalous party in the system, such as one that is small but old.

In the long run, with many more systems drawn into the analysis, a more reliable critical test might be mounted. But it is at least clear at this stage that the systematic disfavoring of small parties, resting as it does on voter sentiments, cannot be written off as any statistical artifact of the type that might infest turnover tables bearing on party continuity and change.

\section{SUMMARY}

Our investigation is motivated by an interest in the way the size of party systems may affect the dynamics of individual party identifications that take place within them, thereby accounting for cross-national variations in their observed properties. In the work reported here we have considered how the choice of analytic method can affect apparent results, especially in working across systems that differ greatly in their party fractionalization. 
Although most past work on the dynamics of partisanship has used discretespace percentage statistics, some problems are better addressed in large party systems with analyses that presume voters see their systems in reasonable degree as continuous spaces.

We have sketched a handsome confirmation of this assumption while demonstrating that continuous-space procedures can capture and isolate the kind of affect bonus that objectifies the special loyalty accorded to the voter's preferred party. The same procedures also cast further light on the issue of limited loyalties to minor parties. While it may be expected that traffic into and out of small parties may be more intense than that for large parties on structural grounds alone, the same analytic procedures showed a tendency of voters to feel an edge of negativism about minor parties even after party distance is controlled.

Acknowledgments. The research reported in this article was made possible by National Science Foundation grant GS-37997. We are also indebted to the archive of the Inter-University Consortium for Political and Social Research (ICPSR) at the Center for Political Studies, the University of Michigan (Ann Arbor, Michigan), for the panel data from election studies in the Netherlands and West Germany as described in note 2. Election panel data from Norway were furnished to us by Ola Listhaug of the University of Trondheim. The principal investigators of the original study were Henry Valen and Bernt Aardal. Anders Skrondal facilitated the data transfer. We profited as well from the technical assistance of James F. Adams and Paul W. Gronke.

\section{NOTES}

1. In most countries where history and measurement have permitted a test, for example, it seems that newly proposed parties are disproportionately attractive to younger voters, and are so even in the subset of cases in which such parties pitch their appeals to older voters and traditional values (as with George Wallace's third-party effort in 1968). These nonobvious behavioral predictions from party identification theory as developed in the United States usually seem to work even in systems where scholars are unable to replicate some of the simpler properties of the measurement.

2. Although our series of investigations invokes a slightly broader set of studies, the empirical data in this report came from four studies. Two were supplied by the ICPSR, including (1) the German Election Panel Study of 1976 (Zentralarchiv Nos. 823, 824, and 825-ICPSR No. 7513) and (2) the Dutch Election Study of 1970-73 (ICPSR Study Number 7261). The French Election Study of 1967-69 is the same as reported in Converse and Pierce (1986). The Norwegian study of 1981-85 is described in our initial acknowledgments.

3. In a paper yet to be published, which we discovered only as this report was in its final revision, Richardson (1991) argues that European party loyalties are most stable and similar in their dynamics to their American counterparts among adherents of traditional European "cleavage" parties, usually class-based ones. He also shows convincingly that these more stable loyalties are buttressed by fuller cognitive party images and higher levels of hostility felt toward the party on the other side of the cleavage. This is most useful in clarifying the 
intervening states that condition partisan dynamics. On the other hand, these cleavage parties also tend to be both old and large. It is not surprising that richer and more consistent cognitive images have accrued for parties that have been the most prominent in national politics for the longest period of time. Given the natural collinearities here, it will not be easy for any of us to tease apart effects associated jointly with age, size, and cleavage-issue programmatic bases.

4. This postulate ignores the Richardson (1986) finding that "out-party hostility" is markedly greater, as measured on thermometer-type scales, in multiparty systems than in the United States. Possibly our next paragraph offers some explanations why this might be so, without subscribing to a more general proposition that larger party systems are also broader psychologically to the voter.

5. We could not deal with every party in extremely fractionalized systems in these terms. That is, while the Dutch system in this period was technically a system of thirty parties or more, two-thirds of these groupings had so few partisans in a limited survey sample (less than ten) that they do not generate stable affect means. Therefore the Dutch sample was treated for this one purpose as a ten-party system (or eight in the middle wave), the Norwegian case as a seven-party system, and the French case as a six-party system. 